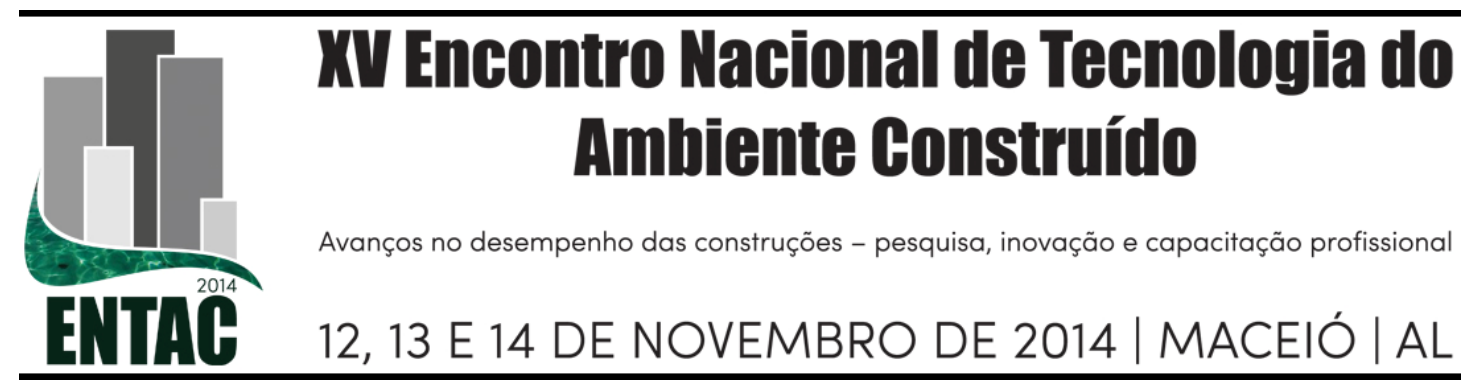

\title{
BENEFÍCIOS DA GESTÃO DE PROJETOS E PLANEJAMENTO EM RELAÇÃO AO IMPACTO AMBIENTAL CAUSADO POR DESPERDÍCIO EM OBRAS.
}

\author{
CARVALHO, Humberto Almansa (1); SOUZA, João Carlos (2); \\ LIBRELOTTO, Lisiane Ilha (3)
}

(1) UFSC, (48) 9970-5729, e-mail: hacxis@hotmail.com, (2) UFSC, e-mail: joao.carlos@ufsc.br,

(3) UFSC, e-mail: lisiane.librelotto@arq.ufsc.br

\begin{abstract}
RESUMO
Este trabalho, fruto de uma discussão realizada em dissertação de mestrado, aborda o impacto ambiental decorrente do desperdício de materiais na etapa de execução de obras de uma edificação. A geração de resíduos, principalmente o entulho gerado pelo setor da construção civil, contribui com mais da metade do entulho gerado no Brasil. Ou seja, estas perdas relativas ao processo ou desperdício de materiais representam aumento de custos dos insumos, uso inapropriado de recursos e custos operacionais de caráter social. Portanto, a geração inadequada de entulhos devido às perdas e ao desperdício na obra causam impactos ambientais relevantes com custos elevados para a sociedade e economicamente inviáveis para a recuperação dos danos ambientais originados em função dos resíduos. É necessário compreender que a ineficiência na produção, que contribui para este desperdício de material e serviço vai muito além do gerenciamento do canteiro de obras. O desperdício é resultado da baixa qualidade do processo de produção, da concepção inadequada do produto dissociada das soluções e elementos construtivos acessíveis à região, ausência de comunicação entre projetos, planejamento, fornecedores e o próprio gerenciamento operacional da execução da obra. Portanto, o objetivo do trabalho é fomentar uma discussão teórica de correlação entre desperdício versus o impacto ambiental. Deste modo é possível recorrer a pesquisas e trabalhos direcionados à gestão de projetos, planejamento de obras, qualidade da produção e demais pesquisas focadas na produtividade e aumento de lucratividade para as empresas e usar procedimentos e métodos para reduzir o impacto ambiental na etapa de execução da obra. Realizouse uma pesquisa bibliográfica acerca de produtividade, impacto econômico e sustentabilidade ambiental. A gestão de desperdício é fruto de pesquisas referentes a controle de qualidade voltado para aumento da produtividade e não por causa do impacto ambiental. No entanto, é possível aplicar gestão de desperdício associada à gestão ambiental. Criando-se uma proporcionalidade entre impacto ambiental e desperdício, é possível aplicar medidas para redução de impacto ambiental que beneficiam métodos de controle de gestão na produção civil através de Gestão de desperdício, e Gestão de resíduos, reutilização dos entulhos das construções. A proposta pretende correlacionar o benefício ambiental aos benefícios econômicos justificando para o meio empresarial que adotar uma gestão para a redução de impacto ambiental também pode ser economicamente atrativa para o setor da construção civil sob o aspecto econômico e social baseado no equilíbrio do tripé da sustentabilidade.
\end{abstract}

Palavras-chave: Impacto Ambiental, Resíduos, Entulhos.

\begin{abstract}
This paper, result of discussion in a master degree research program, describes and analyses the building constructions issues and consequences of material dumping and wasted by building construction in relationship with the environmental degradation. The civil construction dumping represents more than a half of solid waste generated in Brazil, including all over Brazilian industries. It means construction process wastes and material wastes represent an increasing of construction and social costs. Therefore, the inadequate generation of debris due to the waste occurred in the construction work site causes environmental impacts that represents over costs for society. Furthermore it becomes economically
\end{abstract}


unviable for environmental damage recovering. So it's important to comprehend that the inefficiency of production contributes to materials wastes and underproductive services goes far beyond the management of the construction site. The waste is the result of the low quality of the productive process, the inadequate design of the product which is dissociated of constructive solutions, the lack of coherency between plots, blueprints, projects, planning, schedule, material, supply, management and execution of the work. Therefore, this paper intends to promote a theoretical discussion which is possible to relate the problem of dumping $x$ productivity closely associated to the waste and environmental impact. In this way, it is possible to look towards the researches and papers analog to the plot plans and blueprints management of projects, construction management, production control and many more researches focused on productivity, profitability through procedures and methods of reducing environmental impact. The literature intend to compare the research relating to productivity, economic impact, and the researches regarding sustainability focused to environmental impact. The wasting management is originated from quality control programs inherent to productivity. Thus, it is possible to apply measures to the environmental impact reduction for works based on methods of managing control for building construction productivity: dumping control, waste management, reuse of debris of buildings. The proposition intend to link the environmental benefit and the economic benefits justifying that adopting a environmental degradation impact reduction program can become attractive for the civil construction companies and contractors in many aspects such a social and economical aspects supported on sustainability tripod concept.

Keywords: Environmental Impact, Wastes, Dumping.

\section{INTRODUÇÃO}

Desde suas origens, a arquitetura apresenta uma relação íntima entre a concepção, técnica construtiva e matéria-prima. As adequações dos abrigos em relação à disponibilidade de matéria-prima, às condições climáticas de cada região somadas, às peculiaridades de uso e às necessidades sócio-culturais de cada civilização determinaram uma grande variação de estilos arquitetônicos.

A era industrial transforma a produção artesanal em produção de grande escala e o avanço da tecnologia propicia novos produtos disponíveis ao mercado da construção civil. Estes aspectos determinaram um conceito de arquitetura sem fronteiras e universal. Segundo Mascaró, Claro e Schneider (1978), a industrialização gera materiais que não são feitos na obra e sim fabricados e trazidos por vezes em longas distâncias. As estruturas metálicas começam a cobrir grandes vãos com peças delgadas.

Com a revolução industrial, a arquitetura passa a ser fruto de novas possibilidades estéticas e tecnológicas como solução para a grande explosão demográfica da época e do descobrimento de novos materiais (LAMBERTS, DUTRA e PEREIRA, 1997).

A arquitetura internacional adota inicialmente o uso do aço como elemento estrutural e posteriormente o substitui pelo Cimento Portland, refletindo uma sociedade deslumbrada com a tecnologia. Esta sociedade considera a natureza apenas como uma fonte inesgotável de recursos e como depósito de resíduos. A partir da década de 70 este conceito começa a ser revisto quando a crise do petróleo dá um indicativo sobre a escassez dos recursos naturais.

Por um lado, os paradigmas da comunidade internacional sofrem modificações. Por outro lado, até meados dos anos 60 a autoconstrução era o modelo habitacional popular predominante no Brasil. Apenas nos anos 80 , com o crescimento demográfico brasileiro acelerado, onde a população urbana atinge $67,8 \%$ da densidade demográfica, a autoconstrução é substituída por construções habitacionais de larga escala. Esta transição favorece ao desperdício na construção civil.

Nota-se que na fase de construção, ao considerar-se o ciclo de vida de um edifício, existe uma parcela significativa de impacto ambiental, majoritariamente relacionada a 
perdas de materiais, geração de resíduos, interferências e poluição no entorno da obra. Estas perdas relativas ao processo ou desperdício de materiais, representam gastos, uso inadequado de recursos e custos operacionais de caráter social. Portanto, a geração descontrolada de entulhos na obra causa impactos ambientais relevantes com custos elevados para a sociedade e economicamente inviáveis para o poder público proceder a recuperação dos danos ambientais.

A ineficiência na produção, que produz este desperdício de material e serviço, vai muito além do gerenciamento do canteiro de obras. A qualidade do processo de produção depende da concepção do produto, etapa que envolve planejamento e projeto, comunicação com fornecedores através da gestão de suprimentos e o próprio gerenciamento operacional da execução da obra.

Segundo Franchi et al. (1993), o termo perda expressa ocorrências evitáveis e inevitáveis de consumo adicional dos insumos e o termo desperdício expressa a parcela de perdas evitáveis.

As construtoras têm pouca influência sobre o controle de produção e processo de obtenção de matérias-primas, fabricação de materiais e elementos de construção. Inclusive pela expressividade econômica, as construtoras acabam ajustando procedimentos de compra conforme dentro a agenda dos fornecedores. No entanto, as construtoras têm grande potencial de gerenciar quase todos os procedimentos operacionais nas fases de construção para redução de desperdício. Portanto, é de suma importância que a execução da obra conte com recursos de controle partindo do planejamento estratégico, projetos apropriadamente compatíveis e cronograma de obra e controle operacional vinculados as etapas anteriores.

Segundo Maia Lima e Pacha apud Pelacani (2010), a origens das patologias na construção civil em nove diferentes países, têm incidência média de $31 \%$ na etapa de execução da obra e $38 \%$ no projeto.

Souza e Ripper (1998) constataram que estudos preliminares deficientes e anteprojetos equivocados são responsáveis pelo desperdício e transtornos no processo executivo, enquanto as falhas do projeto final de engenharia são responsáveis por manifestações patológicas. Tais manifestações são originadas pela falta de compatibilização entre projetos; especificação inadequada de materiais; detalhamento insuficiente ou errado; detalhes construtivos inexequíveis; falta de padronização das representações e convenções e erros de dimensionamento.

Desta forma, este artigo tem como objetivo perceber as implicações da construção de edifícios e o impacto ambiental gerado na etapa de execução devido ao desperdício de materiais e geração de entulhos ocasionados por deficiência no planejamento. Para tanto será necessário destacar a importância do projeto e planejamento como ferramenta de gestão de desperdício; realizar o controle de desperdício para redução do impacto ambiental e destacar as implicações econômicas e sociais do desperdício na etapa de execução dentro do ciclo de vida do ambiente construído.

\section{REFERENCIAL TEÓRICO}

A revisão bibliográfica aponta majoritariamente para o impacto econômico ocasionado pelo desperdício no canteiro de obra. Naturalmente, encontra-se uma gama maior de trabalhos de pesquisa relacionados à gestão de obras e gestão de processos. Com certa dificuldade encontram-se referências bibliográficas tratando a respeito do impacto social e ambiental gerado pelo desperdício de materiais na construção. No entanto, este 
assunto deverá ganhar notoriedade com a percepção das empresas para o paradigma de sustentabilidade e interesse que a sociedade tem dado para a preservação ambiental.

\subsection{Impacto Econômico}

A consequência do desperdício representa um prejuízo para a construtora sob o aspecto mercadológico que acaba repassando as despesas ao consumidor final através de um produto mais caro que é obtido sem um benefício apropriado.

Segundo Formoso et al (1996), o conceito de perdas na construção civil é com frequência associado unicamente aos desperdícios de materiais. No entanto, as perdas estendem-se além deste conceito e devem ser entendidas como qualquer ineficiência que se reflita no uso de equipamentos, materiais, mão de obra e capital em quantidades superiores aquelas necessárias a produção da edificação. Neste caso, as perdas englobam tanto a ocorrência de desperdícios de materiais quanto à execução de tarefas desnecessárias que geram custos adicionais e não agregam valor. Tais perdas são consequência de um processo de baixa qualidade, que traz como resultado não só uma elevação de custos, mas também um produto final de qualidade deficiente.

A partir do momento em que a engenharia de produção começa a ganhar espaço dentro da construção civil, o tema desperdício se torna assunto em pauta e objeto de estudo relevante dentro do canteiro de obra. A busca pela compreensão das perdas em produtividade e desperdício de material alavanca trabalhos de pesquisa em gestão de obras e gestão de projetos respectivamente nesta ordem cronológica. Nota-se então a relevância do projeto como referencial não apenas para a forma final do produto, mas também para a qualidade da execução do mesmo até a manutenção na de fase pósocupação do edifício.

Segundo Salgado e Adesse (2006), a falta de conhecimento para embasar as escolhas necessárias "ao negócio construir" responsável pela execução e atribuem os erros e equívocos ocorridos nas obras ao projeto, transformando-o no "vilão da qualidade na construção". Conseguem um resultado importante para detecção de problemas originados no projeto.

\subsection{Impacto Social}

A responsabilidade social das empresas não necessariamente entra em choque com o aspecto econômico, pois procedimentos operacionais de segurança estruturados em planejamento refletem na redução de desperdício de trabalho e consequentemente no retrabalho. Por outro lado, o desperdício diminui o desempenho de produção, reduz a segurança do grupo de trabalho, e interfere diretamente no cronograma de obra.

Acima de tudo, as implicações sociais não se restringem apenas ao entulho gerado e atividades de obra, mas refletem em baixa qualidade de um produto final.

Os problemas relacionados ao déficit habitacional no Brasil não se restringem à falta de moradia, mas também a inadequação dessa moradia, com aglomeração de pessoas e ausência de infraestrutura básica (BRASIL, 2007).

Finalmente, os indicadores de desempenho cumprem um papel de fundamental na motivação das pessoas envolvidas no processo. Sempre que uma melhoria esta sendo implantada e importante que um ou mais indicadores de desempenho associados a mesma sejam monitorados e sua evolução amplamente divulgada na organização. Neste sentido, um projeto de melhoria visando a redução de perdas de materiais poderia 
inclusive ser empregado como um instrumento de marketing interno para um programa da qualidade (FORMOSO et al, 1996).

\subsection{Impacto Ambiental}

Desde a etapa de concepção do projeto, desenvolvimento de componentes e a execução da edificação, existem implicações sociais e ambientais. No entanto, apenas na etapa de construção percebem-se as implicações originadas nas etapas de projeto e planejamento.

Abordar o ambiente construído sob o ponto de vista ecológico é trabalhar com novos termos e pensamentos. Um deles é o conceito de entropia, que foi emprestado das Leis da Termodinâmica. Entropia é a energia dissipada ou, como vem sendo utilizada hoje, matéria e energia degradadas. Num sistema de alta entropia, como é a sociedade humana atual, há grande dissipação energética e de matéria que não pode ser reintroduzida ao sistema, torna-o altamente degradante. $\mathrm{O}$ foco seria atingir um sistema econômico, social, espelhada nos sistemas ecológicos em que nada se perde, tudo se transforma (YEANG, 2006)

\section{IMPACTO AMBIENTAL GERADO POR DESPERDÍCIO DE MATERIAIS E RESÍDUOS NA CONSTRUÇÃO CIVIL}

O setor de construção civil é um gerador de resíduos sólidos de grande intensidade. A execução de obra, no ciclo de vida útil da edificação, é a etapa que mais gera resíduo e entulho depois da etapa de demolição. Consequentemente é uma etapa que produz um grande impacto ambiental devido às perdas e desperdícios de material que são destinados a áreas de deposição de entulho. Projetos inadequados, falta de gestão, baixo custo de mão-de-obra e material, manejo de entulho e bota-fora sem responsabilidade ambiental ratificavam a cultura do desperdício na construção civil. Com o surgimento dos programas de gestão, controle de produção, onde o desperdício representa custos para a empresa em um mercado cada vez mais competitivo. A questão do desperdício e descarte dos meios produtivos, durante muito tempo foi tratada de forma secundária, como ramificações de pesquisas de controle de produção e gestão de obras.

Segundo Moraes (1997), a questão do desperdício tem sido tratada subliminarmente à gestão. Quando o foco é o desperdício, o problema gravita como sendo da alçada da administração, como algo inerente à produtividade, como desatrelado do desempenho organizacional, ou ainda como uma questão de eficiência ou mesmo atribuição da qualidade e de seus programas.

Vargas et al (1997), apresenta outros dados alarmantes: o tempo de perda da mão-deobra dos serventes pode atingir $50 \%$ do tempo total, $100 \%$ da argamassa e perdida; e, $30 \%$ dos tijolos e elementos de vedação se transformam em entulho.

No entanto, a consideração de Vargas entre outros de seus contemporâneos em relação ao desperdício estava focada ao controle de qualidade, produção e gestão ainda dissociados da preocupação sobre o impacto ambiental. Considerações a respeito de sustentabilidade na construção civil são recentes. Conceitos ambientais na construção civil são emblemáticos e propagandistas como as ditas construções verdes que não representam verdadeira eficiência para redução de impacto ambiental.

Por outro lado, os fornecedores da indústria da construção civil têm correspondido de forma positiva devido ao endurecimento das leis ambientais e intensificação da fiscalização. Financiadoras, como a Caixa Econômica Federal, já possuem selo ambiental, resoluções do CONAMA prevêem a adequação de novos empreendimentos 
em conformidade com Licenciamentos Ambientais (LAP, LAI e LAO), Estudos de Impacto de Vizinhança EIV e Estudos de Impacto Ambientais EIA-RIMA. A indústria cimenteira adota medidas para melhorar o desempenho de seus processos produtivos quanto à emissão de gases de efeito estufa, incluindo o monitoramento e inventário de emissões, o desenvolvimento de programas de eficiência energética, o uso de adições ao cimento e o uso de combustíveis alternativos. A Associação Brasileira de Cimento Portland ABCP e o SNIC criaram um comitê de mudanças climáticas a fim de focar as ações do setor para o tema, são: Resolução CONAMA sobre fontes fixas existentes, Comitê de Mudanças Climáticas, Fóruns de Meio Ambiente.

Dentre os dados apresentados pela $\mathrm{ABCP}$, foi selecionada a Figura 1: Composição Média de Entulho no Brasil que se refere a composição média de entulho gerado no Brasil. Os dados apresentados no gráfico apontam o significativo impacto ambiental gerado por materiais associados à construção civil. Somando a argamassa, o concreto e a cerâmica, estes materiais representam $92 \%$ do entulho gerado no Brasil. Portanto, o entulho causado por desperdício de materiais na construção civil deve ser tratado seriamente como questão ambiental sem ignorar o aspecto econômico.

Figura 1 - Composição Média de Entulho no Brasil

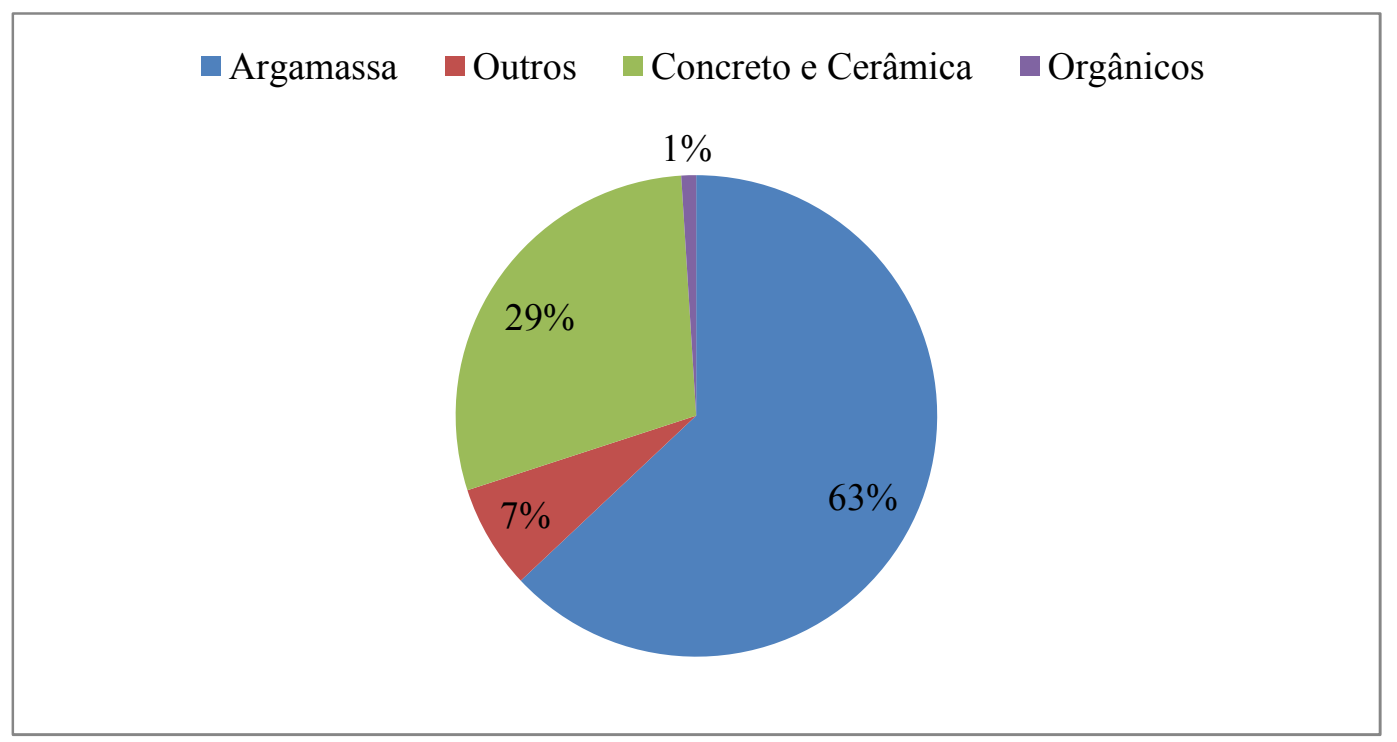

Fonte: ABCP (2012)

Segundo a Resolução $\mathrm{n}^{\circ} .307$ do Conselho Nacional do Meio Ambiente (CONAMA, 2002) - estabelece diretrizes, critérios e procedimentos para a gestão de resíduos da construção, classificando-os em quatro diferentes classes:

- Classe A - resíduos reutilizáveis ou recicláveis como agregados (tijolo, concreto, etc);

- Classe B - resíduos reutilizáveis/recicláveis para outras indústrias (plástico, papel, etc);

- Classe $\mathrm{C}$ - resíduos para os quais não foram desenvolvidas tecnologias viáveis que permitam sua reciclagem (gesso e outros) e

- Classe D - resíduos perigosos (tintas, solventes, etc), ou contaminados (de clínicas radiológicas, instalações industriais e outros). 
Conforme a ABRECON (2014), praticamente todas as atividades desenvolvidas no setor da construção civil são geradoras de entulho. Embora nem toda perda se transforme em resíduo, a quantidade de entulho gerado corresponde, em média, a 50\% do material desperdiçado. Dentre os materiais que mais contribuem com a geração de entulho na construção civil estão a argamassa, o concreto e a cerâmica. Como estes materiais pertencem a classe A podem ser reutilizados ou reciclados, colaborando significativamente para com a gestão do desperdício.

O controle do desperdício é imprescindível para a redução de entulho. Segundo Barros (1998), a argamassa de revestimento, que cai da parede e se torna entulho, atinge 10\% das perdas em uma obra com excelente controle de desperdício. Entretanto, este número pode ser maior: a argamassa caída da parede que se torna entulho atinge $50 \%$ das perdas em uma obra sem qualquer controle de desperdício.

Ao se utilizar como referência os traços apresentados pelo quadro 1, para cada $1 \mathrm{~m}^{3} \mathrm{de}$ produtos derivados do cimento (argamassa ou concreto produzido) tem-se um desperdício médio de $20,3 \mathrm{~kg}$ ou $0,017 \mathrm{~m}^{3}$ de cimento para uma obra com controle de desperdício e $101,5 \mathrm{~kg}$ ou $0,085 \mathrm{~m}^{3}$ de cimento para uma obra sem controle de desperdício. Portanto, o controle de desperdício tem impacto relevante, tanto no aspecto econômico, quanto no aspecto ambiental.

\section{Quadro 1 - Argamassa de cimento e areia}

\begin{tabular}{|l|l|l|l|}
\hline $\begin{array}{c}\text { Traço em } \\
\text { Volume }\end{array}$ & Cimento( Kg $)$ & \multicolumn{1}{|c|}{ Cimento (m3) } & Areia (m3) \\
\hline $1: 6,0$ & 230 & 0.190 & 1.150 \\
\hline $1: 7,0$ & 200 & 0.170 & 1.170 \\
\hline $1: 8,0$ & 180 & 0.150 & 1.200 \\
\hline
\end{tabular}

Fonte: CANDY CCS (2014)

Segundo a ABCP (2013), foram consumidas aproximadamente 71 milhões de toneladas de cimento no Brasil no ano de 2013. Se forem utilizadas as mesmas relações de perdas segundo o exemplo anterior, seria possível afirmar que no Brasil se desperdiça anualmente no Brasil uma média de 19,51 milhões de toneladas de cimento, um número que oscila entre 7,09 a 35,48 milhões de toneladas de cimento. Além da perda, a média de emissão de $\mathrm{CO}_{2}$ lançada anualmente na atmosfera devido ao desperdício seria entre 4,08 a 20,40 milhões de toneladas. Este valor dependeria apenas do controle de desperdício. 
Figura 1 - Emissão média de kilogramas de CO2 por tonelada de cimento

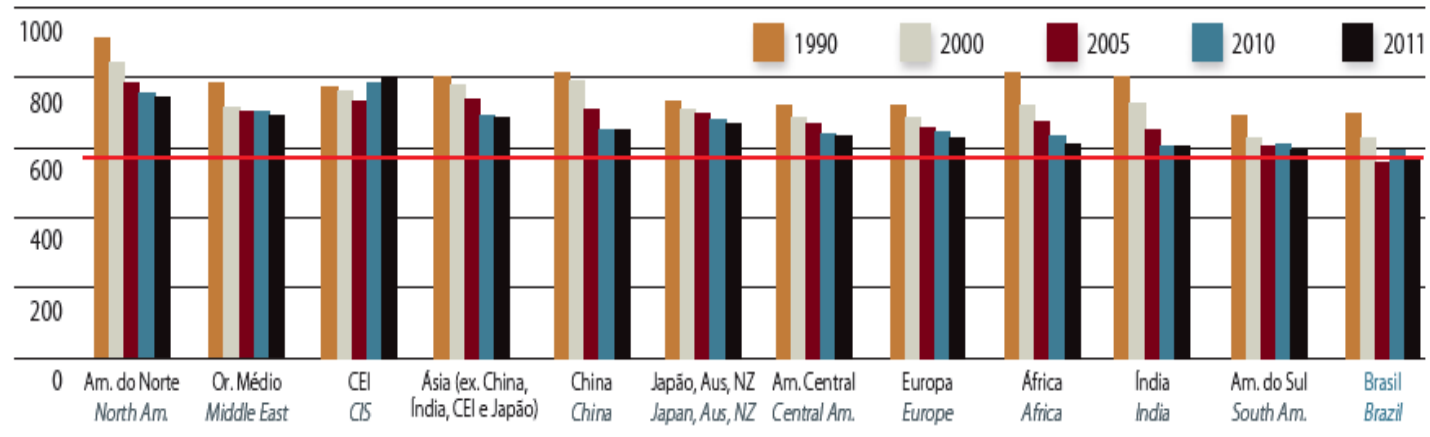

Fonte: WBCSD - CSI (2012)

Portanto, a reutilização desta argamassa residual, pode representar uma redução de desperdício de material, prejuízo financeiro e benefício ambiental. Um exemplo positivo vem do Centro de Referência de Resíduos Sólidos da Construção Civil e Demolições CRCD, que é uma parceria entre o Instituto Nova Ágora de Cidadania - INAC e a Fundação Banco do Brasil para apresentar soluções adequadas na gestão e o manejo dos resíduos sólidos, principalmente os oriundos da construção civil e demolições. As Usinas de Reciclagem de Entulho - UREs favorecem a diminuição do depósito irregular de entulho e contribuem para a redução de extrativismo mineral através da reinserção do agregado reciclado na cadeia produtiva da construção civil.

\section{CONSIDERAÇÕES FINAIS}

Primeiramente, é necessário que o setor da construção civil tome consciência sobre sua significativa constribuição em relação ao acúmulo de entulho, majoritariamente argamassa, cimento e cerâmica em áreas de deposição de resíduos sólidos coforme apresenta o gráfico da ABCP. Assim, é necessário que o setor assuma o compromisso com a responsabilidade social e ambiental para a diminuição de desperdício de materiais e redução de resíduos.

O desperdício de materiais e a redução da geração de entulhos dependem da programação de uma gestão desperdício e gestão de resíduos, respectivamente minoração de erros de processo e destinação do entulho de obra. Esta gestão depende de um efetivo planejamento de produto concluído e compatibilizado em concordância com um planejamento de processo em constante atualização.

A gestão de desperdício tem origem nos programas de qualidade e produtividade. Portanto, o benefício ambiental está agregado nos resultados econômicos positivos. Consequentemente, esta gestão é atrante aos olhos do empresário da construção civil e naturalmente mais fácil de implantar. Por outro lado, a gestão de resíduos ou destinação do entulho de obra, ainda não está associada ao benefício econômico a curto prazo, o que a torna menos atrativa para o setor da construção. Quando realizada pode contribuir para melhorias na qualidade do processo de obra e como bandeira para empresas que se valem da publicidade do selo verde. Pode-se exemplificar com a CRCD, que criou um selo verde chamado selo Entulho Reciclável, concedido às empresas que enviarem resíduos selecionados para a reciclagem. Assim, além de agregar valor à marca da empresa doadora, permitir-se-á também que ela disponha de uma assessoria para manejo do material reciclado na obra. 
A exigência da legislação ambiental, em especial pela Lei da Política Nacional de Resíduos Sólidos (Lei $n^{0}$ 12.305/2010) e Resolução CONAMA 307/2002, de que se realize a segregação dos resíduos nas obras será cada vez mais fiscalizada. Portanto, a redução de resíduos em obra, tanto quanto iniciativas para reutilização do entulho, serão economicamente relevantes para o setor de produção da construção civil que pretende permanecer competitivo no mercado.

\section{REFERÊNCIAS}

Associação Brasileira de Cimento Portland - ABCP. Sistemas construtivos à base de cimento: Uma contribuição efetiva para a sustentabilidade da construção civil. ASSOCIAÇÃO BRASILEIRA DE CIMENTO PORTLAND, Jaguaré, 2013.

Associação Brasileira Para Reciclagem De Resíduos Da Construção Civil - ABRECON. Usos recomendados para agregados reciclados. Disponível em: < http://www.abrecon.org.br/Conteudo/8/Aplicacao.aspx>. Acesso em: 28 fev. 2014.

BARros, M. M. S. de; Sabbatini, F. H.; Seminário Tecnologia e Gestão na Produção de Edifícios: Vedações Verticais. São Paulo EPUSP/PCC, 1998.

BRASIL. Assentamentos precários no Brasil urbano. Secretaria Nacional de Habitação /Ministério das e Centro de Estudos da Metrópole / Cebrap, no âmbito do Projeto PNUD BRA/00/019 - 2007.

CANDY CCS. Fichas de Rendimento. Disponível em: $<$ http://orcamentos.eu/fichasrendimento/fichas-de-rendimento-de-rebocos-e-betonilhas/>. Acesso em: 08 mar. 2014.

CONSELHO NACIONAL DO MEIO AMBIENTE - CONAMA. Resolução No 307: Publicada no DOU no 136, de 17/07/2002, págs. 95-96. 2002.

FORMOSO, C. T. et al. Perdas na Construção Civil: conceitos, classificaçõoes e seu papel na melhoria do setor. Téchne. Sao Paulo, n.23, p.30-33, jul - ago 1996.

FRANCHI, DE CESARE, Claudia; SOIBELMAN, Lúcio e FORMOSO, Carlos Torres. As Perdas de Materiais na Indústria da Construção Civil. Anais do II Seminário de Qualidade da Construção Civil. Porto Alegre, UFRGS-NORIE, 1993.

LAMBERTS, Roberto; DUTRA, Luciano; PEREIRA, Fernando O. Rutkay. Eficiência Energética na Arquitetura. São Paulo, PW, 1997.

MAIA LIMA, Jefferson; PACHA, José Raimundo Serra. Patologias das Estruturas de Concreto Armado com ênfase a Execução.Belém: Centro Tecnológico do Curso de Engenharia Civil da Universidade Federal do Pará - Serviço Público Federal, 2005.

MASCARÓ, Juan L.; CLARO, Anderson; SCHNEIDER, Ingrid E. A Evolução dos Sistemas de Construção com o Desenvolvimento Econômico: uma visão retrospectiva. São Paulo, EDUSP, 2002.

MORAES, Mário César Barreto. As Perdas na Construção Civil: Gestão do Desperdício Estudo de Caso do Condomínio Costa Esmeralda. Florianópolis, UFSC, 1997.

PELACANI, Valmir Luiz. Responsabilidade Na Construção Civil. Cadernos do CREA - PR No 7. Curitiba, 2010.

SALGADO e ADESSE, Importância Do Coordenador Do Projeto Na Gestão Da Construção: A Visão Do Empreendedor, NUTAU, 2006.

SALGADO e DUARTE, O Projeto Executivo De Arquitetura Como Ferramenta para O Controle Da Qualidade Na Obra. IX Encontro Nacional de Tecnologia do Ambiente Construído, Foz do Iguaçú, 2002. 
SOUZA e RIPPER. Patologia, recuperação e reforço de estruturas de concreto. São Paulo : Pini, 1998.

YEANG, Ken. Ecodesign: a manual for ecological design. Londres: Willey Academy, 2006.

VARGAS, C. et al. Avaliacação de perdas em obras - aplicação de metodologia expedita. Anais do $17^{\circ}$ Encontro Nacional de Engenharia de Produção. Gramado, 1997.

WBCSD. The Cement Sustainability Initiative. 10 years of progress - moving on to the next decade. Atar Roto Presse AS. Switzerland. 2012. 